\title{
HUKUM DAN KEADILAN DALAM PERSFEKTIF FILSAFAT HUKUM
}

\author{
Oleh: Edward M.L. Panjaitan \\ e.labuan@gmail.com \\ Universitas Kristen Indonesia, Jakarta, Indonesia
}

\begin{abstract}
Talking about law is about human relations. Talking about human relationships is about justice. Thus, any discussion about the law, clear or vague, is always a discussion about justice too. We cannot talk about the law only to its form as a formal relationship. We also need to see it as an expression of the ideals of justice of the people. The nature of justice is in the eld of philosophy, therefore the problem of justice was initiated by philosophers from time immemorial.
\end{abstract}

Keyword : human relations; justice; the ideals of justice .

\section{Pendahuluan}

Bukanlah suatu pekerjaan mudah untuk membuat rumusan hukum yang diterima oleh semua ahli hukum. Hukum, aspeknya sangat luas (sedemikian kompleks, baik dalam ruang lingkup maupun waktu). Kiranya apa yang dikemukakan oleh Imanuel Kant beberapa ratus tahun yang lalu, masih relevan untuk saat ini. Imanuel Kant mengemukakan "noch suchen die juristien eine definition zu ihrem begriffte vom recht". Oleh van Apeldoorn dijelaskan bahwa tidak mungkin memberikan definisi tentang hukum yang sungguh-sungguh dapat memadai kenyataan. Karena itu hanya memberikan suatu definisi yang umum sebagai pegangan ${ }^{1}$ ).

Defini hukum berbeda dengan konsep hukum. Menurut W. Friedmann, konsep hukum terddiri dari paksaan dan penerimaan masyarakat. Dia mengemukakan "all definition or characterizations of lawveer between two extreme position. One extreme emphasizes its coercive character, the other lays stress on the social acceptance" ${ }^{\prime 2}$ ). JH. Harris mengemukakan bahwahukum adalahmerupakan system peraturandan disisi lain merupakan prosedur ${ }^{3}$ ).

\footnotetext{
1 L.J. Van Apeldoorn, Pengantar Ilmu Hukum, PenerbitPradnya Paramita, Jakarta, 1985, h. 13

2 W. Friedmann, Legal Theory, Columbia University Press, New York, 1967, p. 14.

3 J.H. Harris, Legal Philosophies, Butterworts, London, 1980, p. 259
}

Berbicara mengenai hukum, pertama-tama harus diinsyafi bahwa hukum harus dikaitkan dengan kehidupan social. Para sosiolog berpendapat bahwa hukum adalah gejala social. Dimana ada kehidupan social di situ ada hukum. Hukum adalah pertama-tama merupakan penataan hidup social.

St. Agustinus merumuskan hukum sebagai perintah Tuhan atau kehendak Tuhan yang menghendaki preservasi perintah dan menghukum pelanggaran daripadanya. Sementara oleh Austin, seorang tokoh psoitivis, hukum dirumuskan sebagai tiap-tiap undangundang positif yang ditentukan secara lamngsung atau tidak langsung oleh seorang pribadi atau kelompok orang yang berwibawa bagi seorang anggota atau anggota-anggota suatu masyarakat politik yang berdaulat, dimana yang membentuk hukum adalah yang terttinggi.

Dia mengemukakan adanya beberapa jenis hukum, yaitu :

- Hukum Allah yang mnerupakan suatu moral hidup daripada hukum dalam arti yang sejati.

- Hukum Manusia yaitu segala peraturan yang dibuat oleh manusia, yang dibedakan menjadi :

- Hukum yang sungguh-sungguh (properly so called). Hukum ini adalah undang-undang yang berasal dari suatu kekuasaan politik atau peraturan- 
peraturan pribadi swasta yang menurut undangundang berlaku.

Hukum yang sebenarnya bukan hukum (improperly so called). Yakni peraturan-peraturan yang berlaku bagi sekelompok orang tertentu, seperti suatu kelompok pabrik, klub sepak bola dan sebagainya. Peraturan yang berlaku di bidang ini bukanlah hukum dalam arti yang sungguh-sungguh sebab tidak berkaitan dengan pemerintah sebagai pembentuk hukum.

Apa yang dikemukakan Austin mengenai hukum sebagaimana diuraikan diatas, mendapat kritikan dari H.L.A. Hart yang mengemukakan bahwa sejauh dipandang dari luar, pengertian Austin tentang hukum adalah tepat, sebab benarlah bahwaperintah-perintah yang disebut hukum dikeluarkan oleh seseorang yang berkuasa dan bahwa perintah-perintah itu biasanya ditaati. Tetapi terdapat suatu aspek lain pada hukum yang tidak diperhatikan Austrin, suatu aspek intern. Aspek ini tidak terasa oleh orang-orang yang hidup di luar lingkungan hidup tertentu. Aspek inilah yang oleh Hart disebut sebagai bahwa hukum itu haruslah legal, terlebih dahulu harus diketahui adanya dua jenis kaidah hukum, yaitu :

- Kaidah primer (kaidah hukum yang menentukan kelakuan orang)

- Kaidah sekunder (kaidah hukum yang menentukan berlakunya kaidah primer tersebut).

Kaidah sekunder disebut juga dengan petunjuk pengenal (rules of recognition), sebab mereka itu menyatakan manakah hukum yang sah. Karena adanya petunjuk itu, masyarakat menerima undang-undang dan peraturan-peraturan tertentu sebagai berlaku ${ }^{4}$. Petunjuk pengenal itu nampak dalam pengumuman undang-undang dan peraturan-peraturan pemerintah. Juga dalam surat-surat resmi seperti pengangkatan dalam suatu jabatan. Surat pengangkatan semacam itu dibuka dengan istilah juridis, membaca, menimbang, mengingat dan sebagainya sebagai tanda pengenal $\left.{ }^{5}\right)$.

Lazim diterima bahwa hukum adalah legal bilamana undang-undang dan peraturan-peraturan ditentukan oleh suatu instansi yang berwenang, yakni, pemerintah yang sah dan ditentukan menurut kriteria

4 H.L.A. Hart, The Consept of Law, London, 1979, p153.

5 Theo Huijbers, Filsafat Hukum Dalam Lintasan Sejarah, Liberty Jogyakarta, 1988, h.198-190. yangberlaku. Peraturan-peraturan yang legal itumempunyai kekuatan juridis (validity). Sementara ERugen Ehrlich, seorang ahli sosiologi hukum mengemukakan bahwa hukum yang benar adalah hukum yang berkembang dalam masyarakat. Teorinya terkenal dengan Volksgeist ${ }^{6}$ ).

ThomasAquinas mengemukakan bahwa undangundang adalah tidak sah apabila undang-undang itu tidak benar. Ketidak benaran undang-undang dapat diuji dari segi tujuannya atau dalam hal penulisannya atau dalam hal bentuknya. Undang undang yang demikian bertentangan dengan hukum alam danhukum Tuhan ${ }^{7}$ ). Bandingkan dengan di Indonesia, pengujian suatu undang-undang didasarkan kepada konstitusi atau Undang Undang Dasar Tahun 1945. Inilah yang diatur dalam PEMBENTUKAN Mahkamah Konstitusi melalui UU No. 24 Tahun 2003 tentang Mahkamah Konstitusi, yang sesuai Pasal 10 ayat (1), salah satu kewenangannya adalah untuk menguji undang-undang terhadap Undang Undanga Dasar Negara Repubik Indonesia Tahun 1945.

Friedmann mengemukakan bahwa hukum yang mengingkari nilai-nilai dan martabat manusia tidak dapat dianggap sewbagai hokum. Prof. Fuller berpendapat bahwa agar hukum berlaku harus memiliki moral terdalam. Di lain pihak, J.H. Harris mengemukakan bahwa keadilan merupakan ukuran untukadanya suatu hukum ${ }^{8}$ ).

Bernard Arief Sidharta mengemukakan bahwa kaidah hukum merupakan seperangkat kaidah yang mengatur perilaku para warga masyarakat yang pada suatu waktu dan di tempat tertentu dirasakan sebagai tuntutan keadilan demi terwujudnya keadilan yang mampu membuka peluang bagi setiap orang untuk mencapai kebahagiaan dalam menjalani kehidupan di dunia. Hukum itu bertujuan untuk mewujudkan keadilan yang menjamin terlaksanaanya kepastian dan prediktabilitas di dalam masyarakat. Kepatuhannya tidak diserahkan sepenuhnya kepada kemauan bebas tiap warga masyarakat, melainkan dapat dipaksakan oleh masyarakat secara terorganisasi sesuai dengan kaidah-kaidah hukum yang mengatur penegakan hukum. ${ }^{9}$

6 W. Friedmann, op. cit, p. 250.

7 Ibid, p. 109

8 J.H. Harris, op. cit, p. 260.

9 Bernard Arief Sidharta, Ilmu Hukum Indonesia, Upaya Pengembangan Ilmu Hukum Sistematik Yang Responsif TerhadapPeru- 


\section{Tentang Keadilan}

Telah lama masalah keadilan menjadi pusat perhatian para filsuf Yunani. Pemikiran ini dilatarbelakangi adanya kekacauan sosial, konflik intern, seringnya terjadi pergantian pemerintahan, banyaknya kezaliman dankesewenang-wenangan. Humerusmengemukakan bahwa keadilan masih identik dengan perintah dan kewenganan ${ }^{10}$. Disadari adanya pertentangan antara hukum positif dan keadilan yang didasarkan kepada adanya rasa tidak aman dalam masyarakat, rasa tidak puas terhadap sistem pemerintahan aristokrasi dan banyaknya penyalahgunaan kewenangan, para filsuf Yunani berusaha mencari hakekat keadilan. Seperti Plato yang mendasari konsep keadilan dari ilham (inspiration), dan Aristoteles yang mengembangkannya berdasarkan kajian ilmiah atas dasar prinsip-prinsip rasional dan berlatar belakang model-model politik dan undang-undang yang telah ada. Walaupun keduanya sependapat bahwa keadilan merupakan aspek yang mutlak dari "kebajikan".

Karya Plato mengenai keadilan termuat dalam Republic dan The Laws. Keadilan menurut Plato adalah kebijakan dalam arti keselarasan dan keseimbangan batin. Aristoteles dalam Retorica mengemukakan bahwa keadilan itu adalah cita-cita semua orang dan harus dipertahankan dalam semua bidang kehidupan ${ }^{10}$. Kemudian oleh Ulpianus, seorang ahli hukum Romawi menegaskan dalam Digesta - Institutiones dael I sebagai berikut: Justitia est perpetua et constans voluntas jus suum cuique tribuendi, keadilan adalah suatu keseimbangan yang berisi berilah kepada seseorang apa yang menjadi bagian/haknya, suum cuique tribuere, memberikan apa yang menjadi bagian/hak seseorang ${ }^{11}$.

Ternyata bahwa apa yang dikemukakan oleh Ulpianus di atas, merupakan pengembangan dari teori keadilan Aristoteles yang membagi keadilan atas :

- Justitia Commutative

Keadilan yang memberikan kepada masing-masing bagiannya atas dasar persamaan.

\footnotetext{
bahan Masyarakat, Genta Publishing, Yogyakarta, 2013, hala$\operatorname{man} 7$.

$10 \quad$ W. Friedman, op. cit, p 6.

11 Herman Sihombing, Keadilan diBidang Hukum, Makalah Disampaikan pada Musywarah Nasional I, Partisipasi Kristen Indone-

sia, Jakarta, dimuat dalam Majalah Honeste Vivere No.28Tahun VII, Desember 1995, hjalaman 79.
}

\section{- Justitia Distributiva}

Keadilan yang memberikan kepada masing-masing bagiannya atas dasar perbedaan, dimana diperhitungkan perbedaan kualitasnya. Terjadi ketidak adilan apabila yang sama diberlakukantidak sama, dan yang tidak sama diberlakukan sama. Demikian yang dialami Yesus, pada saatdisalibkan di kayu salib di Golgota berdasarkan putusan Pontius Pilatus.

\section{- Justitia Vindicativa}

Keadilan yang memberikan kepada masing-masing bagiannya atas dasar keseimbangan (proporsi) masing-masing, misalnya hukuman seimbang dengan kejahatan.

- Justitia Creativa

Keadilan yang memberikan kepada masing-masing bagian kebebasan untuk menciptakan sesuatu atas kreativitasnya di bidang ilmu dan kebudayaan.

\section{- Justitia Prativa}

Keadilan yang memberikan pengayoman kepada manusia. Pertimbangan didasarkan kepada bahwa semuakekuasaanmanusia terhadap manusia harus dibatasi, yaitu pembatasan terhadap kekuasaan yang membatasi hak dan kewajiban dasar manusia.

\section{- Justitia Legalis}

Kebajikan yang menyeluruh dalam hubungannya dengan kepentingan umum dalam masyarakat. Agar penguasa setia kepada janji dan bertindak menurut itikad baik.

Dun Scotus mengemukakan bahwa hanya pada Tuhan ada keadilan, karena diatas Tuhan tidak ada hukum ${ }^{12}$. Sementara Kelsen mengemukakan bahwa terdapat dua tipe dasar perihal keadilan, yaitutipe rasionalistis dan tipe metafisis. Tokoh rasionalistis adalah Aristoteles yang berusaha mencari hakekat keadilan melalui kajian ilmiah secara logis. Sedangkan tipe metafisis yang dipelopori Plato, percaya bahwa keadilan itu ada akan tetapi sebagai kualitas yang fungsinya tidak dapat diamai oleh manusia. Keadilan terdapat dalam dunia lain, di luar pengalaman manusia, dan akal manusia yang esensial bagi keadilan tunduk pada cara-cara Tuhan yang tidak dapat diubah.

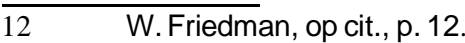


Plato mendasarkan keadilan pada pengetahuan yang baik yang ada di luar "dunia luar" yang hanya diperoleh dengan kebijaksanaan. Di lain pihak, Friedman mengemukakan bahwa dasar teologis memberikan dasar yang paling sederhana dan sejati untuk cita-cita keadilan. Dan St. Agustinus mengakui bahwa keadilan hanyalah merupakan tertib yang memberikan bagian kepada setiap pihak secara proporsional ${ }^{13}$.

Teori keadilan dari Del Vechio diawali dengan rumusan kualitas ganda dari manusia. Manusia sekaligus fisik dan metafisik, keduanya merupakan prinsip alam. Sebagai bagian dari alam, ia tidak dapat membedakan antara baik dan buruk, tetapi sebagai makhluk yang berakal ia mempunyai kemungkinan memutuskandengan bebas terhadap apa dalam dirinya sendiri. Sebagai makhluk yang berakal yang melebihi dan memahami alam, manusia mempunyai dalam dirinya "benih keadilan yang abadi". Benih keadilan adalah suatu ita dan perasaan. Oleh karenanya, esensi keadilan adalah subjektivitas dalam dirinya (alterita), yaitu pemikiran serempak tentang beberapa masalah pokok pada tingkatan yang sama, dari ini timbul unsure persamaan dan timbal balik.

\section{Keadilan dalam Hukum Positif di Indonesia}

Untuk mengkaji keadilan dalam hukum positif di Indonesia, terlebih dahulu harus disepakati apa yang dimaksud dengan hukum. Dalam arti yang luas, hukum adalah segala peraturan yang karena isinya mengikat dan berlaku seecara umum bagi seluruh rakyat Indonesia. Tegasnya, adalah apa yang terdapat dalam TAP MPR(S) No. XX/MPR(S)/1966 jo TAP MPR No. V/ MPR/1973 tentang Tata Urutan Peraturan Perundangan Republik Indonesia, yaitu :

- UUD 1945

- TAPMPR

- Undang Undang dan Peraturan Pemerintah Pengganti Undang Undang

- Peraturan Pemerintah

- Keputusan Presiden

- Instruksi Presiden

- Dan Seterusnya

$\overline{13}$ Soerjono Soekatmo, Teori Yang Murni Tentang Hukum, Penerbit Alumni Bandung, 1985, hal 63.
Sementara itu, melalui UU No. 11 Tahun 2012 tentang Pembentukan Peraturan Perundang Undangan ditetapkan yang merupakan hukum dalam pengertian materil adalah :

- UUD Tahun 1945

- TAPMPR

- Undang Undang

- Peraturan Pemerintah Pengganti Undang Undang (Perpu)

- Peraturan Presiden (Perpres)

- Peraturan Pemerintah

- Keputusan Presiden

- Instruksi Presiden.

Di luar ini masih terdapat hukum positif, yaitu hukum Islam dan hukum adat. A.S.S. Tambunan, berpendapat bahwa akibat dari TAP MPR(S) No. XX ini terjadilah kekacauan dalam hukum Indonesia hingga sekarang, sehingga perlu dicabut dan dinyatakan tidak berlaku ${ }^{14}$. Dengan TAP MPR(S) No. XX tersebut, Indonesia dapat dikatakan menganut paham legisme, yang hanya mengakui hukum tertulis, padahal dalam kenyataannya tidak demikian. Hukum adat tetap diakui, khususnya terhadap pengakuan atas hak ulayat, walaupun masih bersifat setengah-setengah ${ }^{15}$.

Dengan memperhatikan wujud hukum positif Indonesia, khususnya yang berada di bawah UUD 1945 dapatlah dikemukakan bahwa perwujudan keadilan dalam peraturan perundang-undangan sangatlah berkurang, bahkan dalam beberapa hal tertentu sama sekali terabaikan. Apa yang dikemukakan Thomas Aquinas di atas dapat disebut disini. Bahwa hukum yang terwujud dalam peraturan perundang-undangan di Indonesia adalah tidak benar dan tidak sah. Dan hakekat yang paling dalam adalah bahwa undangundang itu bertentangan dengan kehendak Tuhan. Hukum tersebut tidaklah hukum yang hidup(volksgeits) dari Eugen Erhlich.

Dimanakah letak ketidak adilan itu? Ketidak adilannya dapat dilihat dalam hal tujuannya (tidak

\footnotetext{
14 A.S.S. Tambunan, TAP MPR(S) No. XX/MPR(S)/1966, Makalah disampaikan sebagai bahan kuliah pada Program Pascasarjana Magister IImu Hukum Universitas Kristen Indonesia, Jakarta, 1999.

15 Himpunan Komentar Atau Tanggapan Putusan-Putusan Pengadilan Oleh Pakar Hukum Universitas Negeri dan Swasta Di Indonesia, Jilid I, Departemen Kehakiman Republik Indonesia, 1998, hal 194.
} 
mengacu kepada kebaikan masyarakat, tetapi kepada nafsu dan kesombongan pembuat undang-undang), atau dalam hal penulisannya (undang-undang yang dibuat melampaui kewenangan yang ada padanya) ${ }^{16}$, atau dalam hal bentuknya (bilamana sejumlah beban diletakkan secara tidak sama terhadap masyarakat).

Dalam prakteknya, wujud keadilan dapat dilihat secara nyata dalam setiap keputusan Hakim yang mengakhiri persengketaan para pihak melalui lembaga peradilan. Dalam mengambil putusannya, sistem peradilan (hukum formal) Indonesia sangat memungkinkan ketidak adilan, oleh karena putusan Hakim sangat tergantung kepada keyakinan hukumnya (sunjektivitas). Jurisprudensi merupakan hal yang paling penting untuk melihat pengakuan dan penerapan keadilan dalam hukum positif di Indonesia disamping undang-undang itu sendiri. Jurisprudensi merupakan hukum dalam prakteknya. Pancasiladanfilosofinya telah dituangkan dalam Batang Tubuh UUD 1945 dalam pasal-pasalnya. Pasalnya UUD itu dirumuskan dalam hukum perundang-undangan dalam segala bentuknya adalah hukum in Agemen dan in Abstracto.

\section{Penutup}

Membicarakan hukum adalah membicarakan hubungan antar manusia. Membicarakan hubungan antar manusia adalah membicarakan keadilan. Dengan demikian, setiap pembicaraan mengenai hukum, jelas atau samar-samar, senantiasa merupakan pembicaraan mengenai keadilan pula. Kita tidak dapat membicarakan hukum hanya sampai kepada wujudnya sebagai suatu hubungan yang formal. Kita juga perlu melihatnya sebagai ekspresi dari cita-cita keadilan masyarakatnya. Hakekat keadilan ada dalam lapangan filsafat, olehkarenanyapermasalahankeadilandiawali oleh para filsuf sejak jaman dahulu kala.

\section{Daftar Pustaka}

Apeldoorn, L.J. van, Prof. Mr. Dr., Pengantar Ilmu Hukum, Penerbit Pradnya Paramita, Jakarta, 1985.

Arief Sidharta Bernard, Ilmu Hukum Indonesia, Upaya Pengembangan Ilmu Hukum Sistematik Yang Responsif Terhadap Perubahan Masyarakat, Genta Publishing, Yogyakarta, 2013

Arifin Muhammad, Teori Dan Filsafat Hukum, Susunan I, Penerbit Rajawali, Jakarta, 1990.

Departemen Kehakiman Repubik Indonesia, Himpunan Komentar atau Tanggapan PutusanPutusan Pengadilan Oleh Para Pakar Hukum Universitas Negeri Dan Swasta Di Indonesia, Jilid I, Jakarta, 1998.

Departemen Kehakiman Republik Indonesia, Himpunan Komentar Atau Tanggapan Putusan-Putusan Pengadilan Oleh Pakar Hukum Universitas Negeri dan Swasta di Indonesia, Jilid II, Jakarta 1998.

Friedman W, Legal Theory, Columbia University Press, New York, 1967.

Hart. H.L.A., The Concept of Law, ed. 10, London, 1979.

Harris J.H, Legal Philosophies, Butterworths, London, 1980.

Huijbers Theo, Filsafat Hukum Dalam Lintasan Sejarah, Penerbit Liberty, Jogjakarta, 1988.

Soekamto Soerjono, Teori Yang Murni Tentang Hukum, Penerbit Alumni, Bandung, 1985. , Teori Dan Filsafat Hukum,

Susunan II, Penerbit Rajawali, Jakarta, 1990.

Tambunan, A.S.S., TAP MPR(S) No. XX/

MPR(S)/1966, Makalah disampaikan sebagai bahan kuliah Sejarah Hukum pada PMIH-PPS UKI tahun 1999.

Majalah Honeste Vivere No. 28 Tahun VII, Desember 1995. 
Tô-râ: Volume 4 Nomor 2, Agustus 2018, Rospita A. Siregar, hal. 43-46

\author{
16Himpunan Komentar Atau Tanggapan \\ Putusan-Putusan Pengadilan Oleh Pakar Hukum \\ Universitas Negeridan Swasta Di Indonesia, Jilid \\ II, Departemen Kehakiman Republik Indonesia, \\ 1998, hal 400 .
}

